\title{
INVENTÁRIO DE MACROINVERTEBRADOS ASSOCIADO AOS FATORES FÍSICOS E QUÍMICOS DA ÁGUA, EM TRÊS IGARAPÉS DO MUNICÍPIO DE CAPANEMA, NORDESTE PARAENSE
}

\author{
José Moacir Ferreira Ribeiro; Zilda de Fátima Costa, Ieda Maria da Silva, Antônio Pereira Júnior; \\ Edmir dos Santos Jesus \\ DOI:10.4322/978-85-455202-1-4-15
}

INTRODUÇÃO

\begin{abstract}
Os invertebrados de maneira geral compõem um grupo de grande importância para a ecologia de diversos ambientes, principalmente o aquático, participando diretamente das cadeias alimentares, muitas vezes representando um elo entre os produtores e consumidores primários, principalmente algas, microrganismos e peixes.

Estes grupos ocupam praticamente todos os tipos de ambientes, estando adaptados a diferentes condições ambientas, pois possuem espécies altamente exigentes em determinados fatores e ao mesmo tempo tolerantes a outros, possuem vários tamanhos, são abundantes com o ciclo de vida aquática longo, o que favorece sua ampla utilização nos programas de monitoramento dos rios (MERRIT; CUMMINS, 1996).

A macrofauna da maioria dos corpos aquáticos é composta de uma variedade de grupos taxonômicos, incluindo os filos Arthropoda, Oligocaeta, Nematoda e Platyhelminthes (MERRIT; CUMMINS, 1996; EATON, 2003), sendo sua abundância e diversidade influenciadas por características ambientais como variáveis físico-químicas, tipo de sedimento, teor de matéria orgânica, profundidade e presença de macrófitas (CARVALHO; IEDA, 2004; SMITH et al., 2003; VIDAL-ABARCA et al., 2004).

Os Macroinvertebrados, portanto, fazem parte da dinâmica de diversos rios, riachos, igarapés e lagoas, servem de alimentos para outros grupos animais como peixes e crustáceos, participando diretamente da ciclagem de nutrientes do bioma onde vivem, por isso são indicados para avaliar a qualidade da água em função de seu reflexo imediato às mudanças ambientais (Esteves, 1998).

Estudos destes grupos principalmente no Nordeste Paraense são escassos, Monteiro-Santos (2008) desenvolveu pesquisas com insetos aquáticos no nordeste e sudeste paraense no período de seca e chuva mostrando que as ordens mais abundantes foram Diptera, Trichoptera, Plecoptera, Ephemeroptera, Heteroptera, Odonata, Megaloptera, Coleoptera e Lepdoptera. Esta pesquisa tem o objetivo de inventariar, avaliar e comparar a comunidade de Macroinvertebrados de três igarapés do município de Capanema, nordeste Paraense.
\end{abstract}

\section{OBJETIVO}

Analisar e avaliar a Fauna de Macroinvertebrados de Três igarapés do município de Capanema, Estado do Pará.

\section{HIPÓTESE ABORDADA}

Existe diferença entre a fauna de Macroinvertebrados e os aspectos físico-químicos da água nos três igarapés analisados, no município de Capanema, Pará. 


\section{METODOLOGIA}

\section{ÁREA DE ESTUDO}

O município de Capanema $\left(01^{\circ} 18^{\prime} 53,6^{\prime \prime} \mathrm{S} 47^{\circ} 05^{\prime} 45,1^{\prime \prime} \mathrm{W}\right)$ está localizado a $160 \mathrm{~km}$ de Belém, capital do estado (Figura 1). A área escolhida para a realização deste trabalho apresenta como características principais uma cobertura vegetal de floresta secundária, clima do tipo AM, segundo a classificação de Köppen, equatorial quente e úmido, com uma estação mais chuvosa, entre os meses de dezembro a maio, e outra menos chuvosa, entre os meses de junho a novembro. A precipitação média está em torno de $2.200 \mathrm{~mm}$ anuais. A temperatura máxima varia entre $29^{\circ} \mathrm{C} \mathrm{e} 31^{\circ} \mathrm{C}$, sendo que a temperatura média fica em torno de $26^{\circ} \mathrm{C}$.

A umidade relativa do ar se apresenta entre os $78 \%$ a $93 \%$. A drenagem municipal da área é representada pelo rio Quatipuru e seu formador o rio Açaiteua, os quais constituem o limite com o município de Bragança. A Leste passa no distrito de "Mirasselva" e se dirige para o Norte. Um de seus subafluentes, o igarapé Açu, também conhecido como Alagado do Segredo ou Vale Santa Helena, recebe uma série de cursos menores, enquanto seu afluente, Vale do Basílio, serve de limite, ao Norte, com o município de Primavera. A sudoeste do Município, próximo à sua sede, encontramse as nascentes do rio Urucuri, afluente da margem direita do Rio Peixe-Boi e o seu tributário, pela margem esquerda, o Rio Capanema, que faz limite com o município de Peixe-Boi. O solo é formado por Latossolo Amarelo, com textura média e Concrecionários Laterítico, Areia Quartzosa e Podzol Hidromórfico, além de solos Hidromórficos indiscriminados e solos aluviais, em associações (IBGE, 2011).

Figura 1 - Mapa esquemático dos pontos de coleta da área de estudo do Nordeste Paraense.

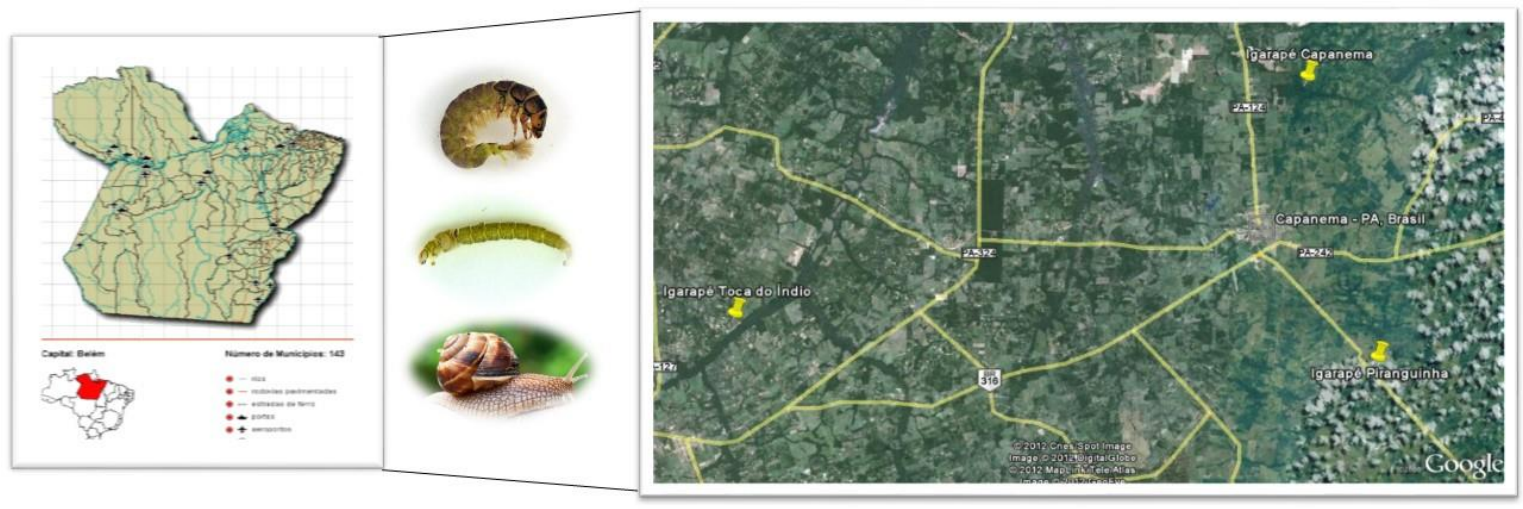

Fonte: Ribeiro (2019).

\section{MÉTODO DE COLETA}

As coletas foram realizadas no período de 06/06/2012 a 15/10/2013. Foram estabelecidos três pontos de coletas a cada $15 \mathrm{~m}$, em três igarapés do município de Capanema (Figura 2).

Figura 2 - Desenho amostral com um trecho no curso do igarapé.

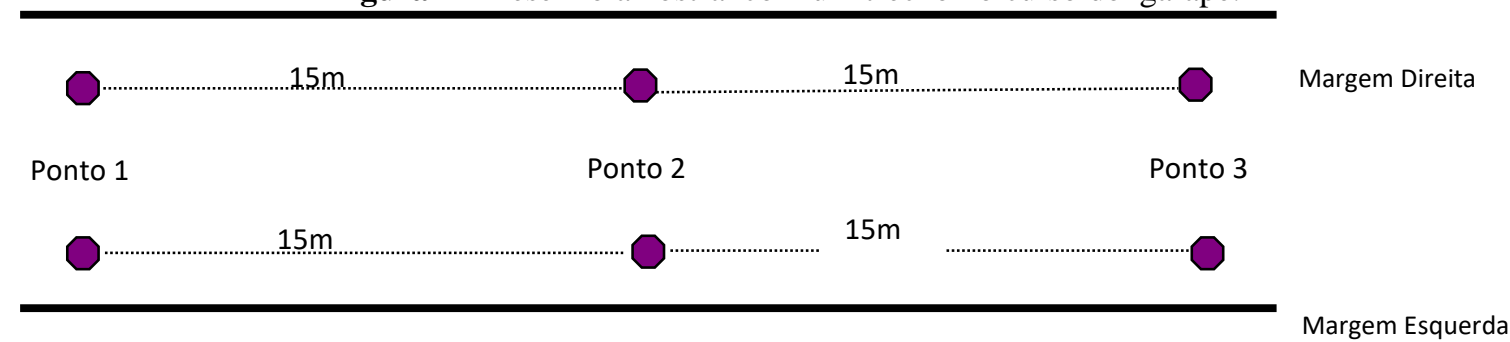

Ponto de coleta 
Fonte: autores (2018)

Os pontos amostrados foram distribuídos ao longo dos igarapés. Em cada ponto foram coletadas porções de serapilheira com rede de mão chamada rapiché (Figura 3a-e). O esforço de coleta foi padronizado em 2 horas, uma hora para cada pessoa. Com relação aos fatores físico-químicos, neste estudo mensuramos apenas três parâmetros para caracterizar as condições de qualidade da água desses igarapés, essas medidas foram realizadas "in loco", através de aparelhos específicos (Figura 4). Foram analisados o potencial Hidrogeniônico (pH0, Oxigênio dissolvido (OD) e condutividade elétrica (CE).

Logo após a coleta as amostras foram transferidas para bandejas (Fig. 3b) em seguida triadas e acondicionados em frascos contendo álcool 70 - 80\%. Os exemplares coletados foram levados ao laboratório da Universidade Federal do Pará (Polo-Capanema) e ao Laboratório de Entomologia do Museu Paraense Emílio Goeldi (Belém-PA), onde, após identificação, serão depositados na coleção do MPEG. Foi realizada uma estatística descritiva utilizando os índices de Shannon-Wiener, Simpson e correlação linear de Pearson.

Figura 3 - A- Aspecto da margem do igarapé; B- Curso d'água do Igarapé Piranguinha; C, D-Coleta de serapilheira no leito do igarapé Piranguinha; E- Coleta no igarapé do Toca do índio e F- Triagem e identificação do material em laboratório

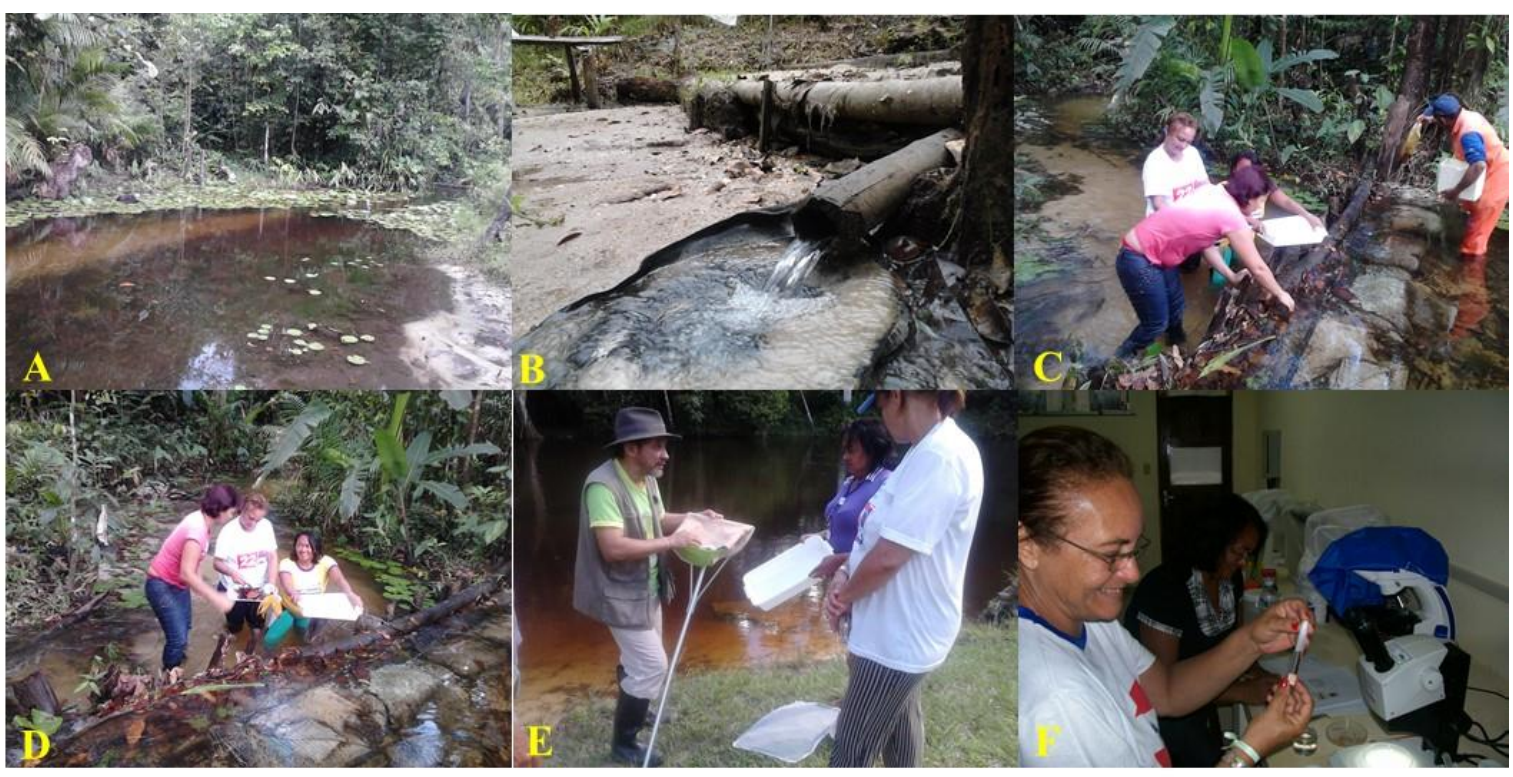

Fonte: Ribeiro e Costa, 2018

Figura 4- Aparelhos para registrar os fatores físicos e químicos da água (a-Condutividade elétrica, b-oxigênio dissolvido e c-peagâmetro).
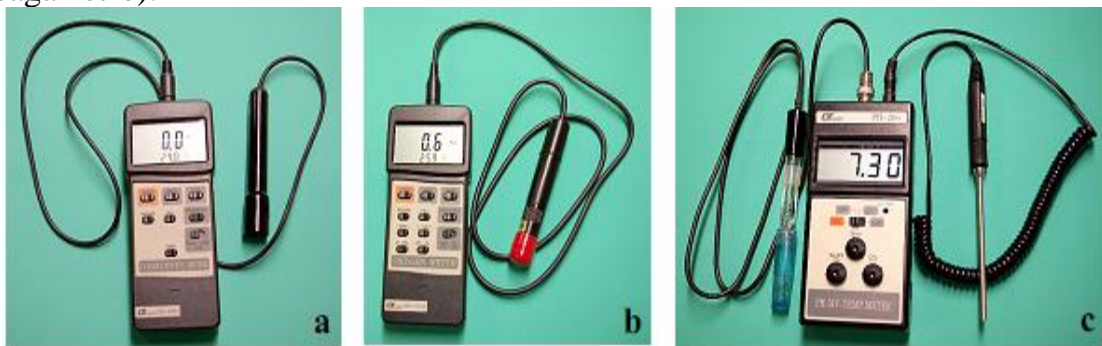

Fonte: Ribeiro e Costa, 2018. 


\section{TEMPERATURA, PH, OXIGÊNIO DISSOLVIDO E CONDUTIVIDADE ELÉTRICA}

Vários trabalhos têm indicado a temperatura como fator que influencia os aspectos físicoquímicos da água em conjunto com os fatores biológicos dentre outros, como gases que estão dissolvidos na água. A temperatura apresentou média entre $26^{\circ} \mathrm{C}$ no Igarapé Toca do Índio, $25{ }^{\circ} \mathrm{C}$ no Igarapé Piranguinha e $27^{\circ} \mathrm{C}$ no Igarapé Capanema. Um estudo realizado por Ribeiro e Silva (2009) (trabalho não publicado), na Bacia do rio Peixe-Boi com insetos aquáticos, mostrou uma variação semelhante, o que corrobora com os dados deste estudo, indicando características térmicas comuns dessas águas nos períodos de seco e chuvoso (Tabela 2).

Geralmente valores de $\mathrm{pH}$ ácidos ou alcalinos, variam de 6,0 a 8,0 e são encontrados na maioria dos ambientes (WETZEL, 1983). O pH de maior intensidade foi observado no igarapé Capanema (7.4) provavelmente pelo fato deste igarapé se localizar nas proximidades da cidade de Capenema, onde resíduos são lançados diariamente nos córregos da cidade que cruzam em algum momento este igarapé (Figura 6). Os valores para os dois outros igarapés apresentaram-se homogêneos entre os ambientes (5.8) e (5.5).

Figura 6 - Potencial hidrogeniônico $(\mathrm{pH})$ analisados nos três igarapés do município de Capanema - PA.

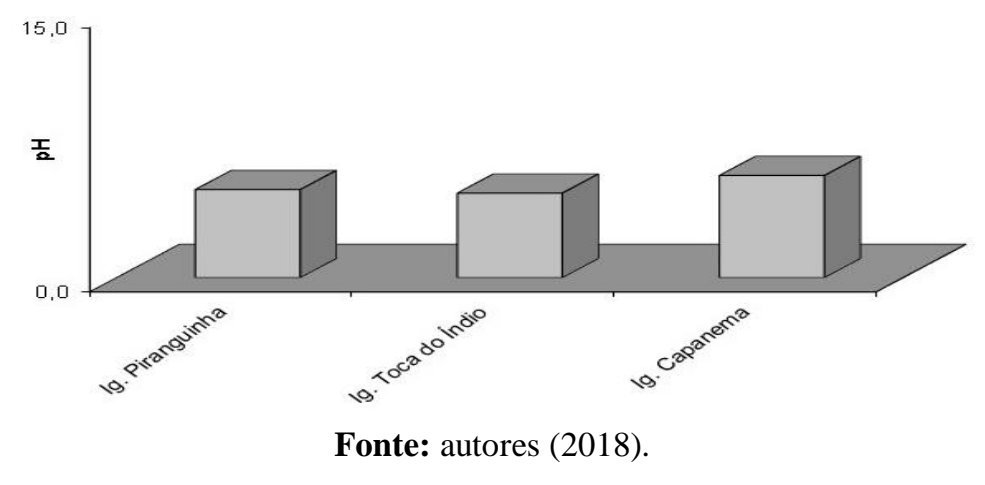

O oxigênio dissolvido analisado nos córregos obteve os seguintes parâmetros: igarapé toca do índio: 6.0-6.5 mg/L; igarapé Piranguinha: 5.0-7.0 mg/L; igarapé Capanema 4.0-3.5 mg/L (Figura 7).

Figura 7- Oxigênio dissolvido $\left(\mathrm{O}_{2}\right)$ analisados nos três igarapés do município de Capanema - PA.

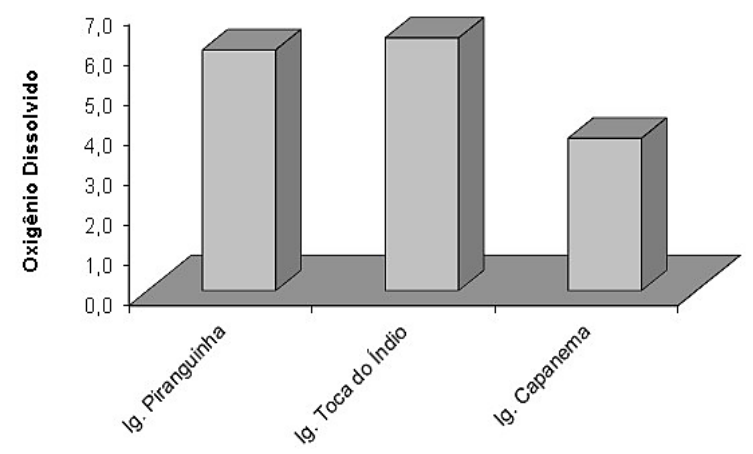

Fonte: autores (2018)

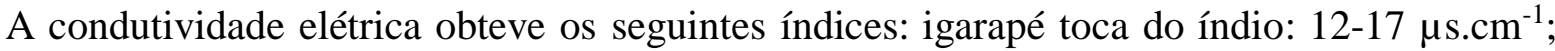
igarapé Piranguinha: $13.5-14.5 \times \mu{\mathrm{s} . \mathrm{cm}^{-1}}^{\text {; }}$ igarapé Capanema: 32-66 $\mu \mathrm{s.cm}{ }^{-1}$ (Figura 8). 
Figura 8- Condutividade elétrica (CE) analisada nos três igarapés do município de Capanema-2PA.

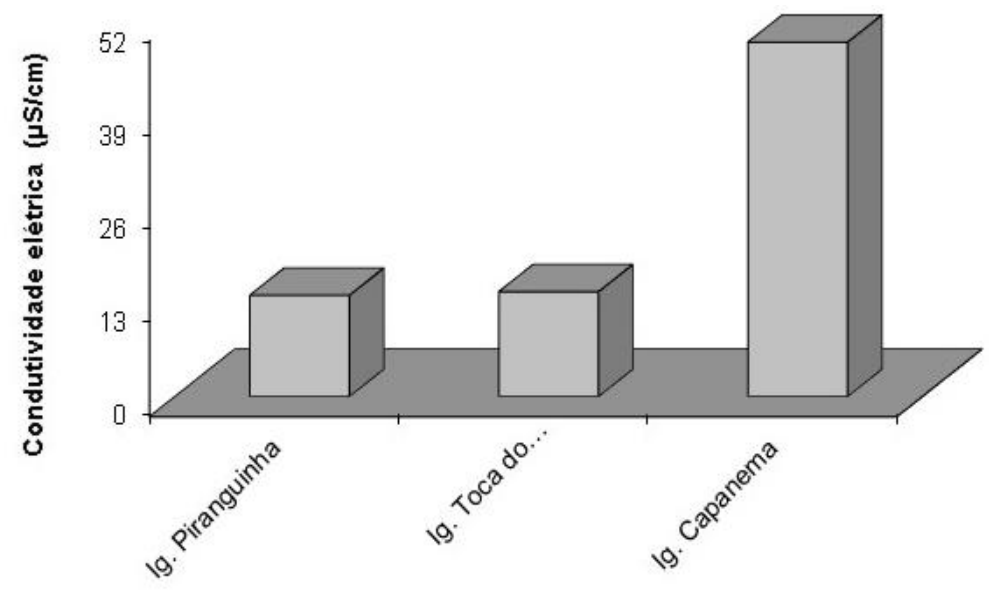

Fonte: autores (2018)

O igarapé que obteve o menor valor de oxigênio foi o igarapé Capanema, provavelmente em função dos resíduos que são jogados em seu leito advindo do saneamento da cidade, o que evidentemente prejudica a permanência da fauna de Macroinvertebrados em seus respectivos microhabitat. Já a condutividade elétrica foi muito alta no mesmo igarapé indicando um forte desequilíbrio na dissociação de íons dissolvidos na água, sendo um dos fatores de migração desses organismos para ambientes menos poluídos, a proliferação de macrófitas aquáticas em vários trechos desse igarapé, também é um indicativo de poluição. Há uma inter-relação entre condutividade elétrica e $\mathrm{pH}$, ambas sujeitas a alternância de precipitação pluviométrica anual e a natureza geológica da bacia hidrográfica, o que certamente tem grande influência na composição e abundância de Macroinvertebrados, principalmente uma maior riqueza de moluscos em ambientes alcalinos, no semiárido paraibano (ABÍLIO, 1997; 2002; 2007).

Abílio (2007) também encontrou certo favorecimento na riqueza de Macroinvertebrados (Moluscos) em águas com baixo $\mathrm{pH}$ e alta condutividade elétrica (Tabela 1), o que corrobora com este estudo amazônico onde foi observado uma grande quantidade de moluscos coletados no igarapé Capanema com destaque para as famílias Pilidae (Molusca) e Polycentropodidae (Trichoptera).

Tabela 1 - Parâmetros físicos e químicos da água com média e desvio padrão, no município de Capanema, Pará.

$\mathbf{T e m p}=$ Temperatura da água, $\mathbf{p H}=$ potencial hidrogênioiônico, $\mathbf{C} . \mathbf{E}=$ condutividade elétrica, $\mathbf{O}$. $\mathbf{D}=$ oxigênio dissolvido na água, Larg= largura do igarapé, Prof= profundidade do igarapé, Veloc = velocidade e Vaz= vazão.

\begin{tabular}{|c|c|c|c|c|c|c|c|c|}
\hline Localidade & $\begin{array}{c}\text { Períodos } \\
\text { do ano }\end{array}$ & Valores & $\begin{array}{c}\text { T. Água } \\
\left({ }^{\circ} \mathbf{C}\right)\end{array}$ & pH & $\begin{array}{c}\text { C.E. } \\
(\mu \mathrm{S} / \mathrm{cm})\end{array}$ & $\begin{array}{c}\text { O.D. } \\
(\mathrm{mg} / \mathrm{l})\end{array}$ & $\begin{array}{l}\text { Veloc. } \\
(\mathrm{m} / \mathrm{s})\end{array}$ & $\begin{array}{l}\text { Vazão } \\
\left(\mathrm{m}^{3} / \mathbf{s}\right) \\
\end{array}$ \\
\hline \multirow[t]{4}{*}{ g.Piranguinha } & \multirow[t]{4}{*}{ Chuva } & Mínimo & 24.0 & 4.2 & 13.5 & 5.0 & 0.51 & 0.52 \\
\hline & & Máximo & 26.5 & 5.8 & 14.5 & 7.0 & 0.66 & 0.52 \\
\hline & & Média & 25.3 & 5.0 & 14.0 & 6.0 & 0.59 & 0.52 \\
\hline & & $\mathrm{DP}$ & 1,8 & 1,1 & 0,7 & 1,4 & 0,1 & 0,0 \\
\hline \multirow[t]{4}{*}{ Ig. Toca do Indio } & \multirow[t]{4}{*}{ Chuva } & Mínimo & 25.5 & 4.0 & 12.0 & 6.0 & 0.80 & 0.36 \\
\hline & & Máximo & 26.5 & 5.5 & 17.0 & 6.5 & 1.0 & 0.36 \\
\hline & & Média & 26.0 & 4.8 & 14.5 & 6.3 & 0.90 & 0.36 \\
\hline & & $\mathrm{DP}$ & 0.7 & 1.1 & 3.5 & 0.4 & 0.1 & 0.0 \\
\hline \multirow[t]{4}{*}{ Ig. Capanema } & \multirow[t]{4}{*}{ Chuva } & Mínimo & 26.5 & 4.1 & 32.0 & 4.0 & 1.0 & 1.50 \\
\hline & & Máximo & 27.0 & 7.4 & 66.0 & 3.5 & 1.0 & 1.50 \\
\hline & & Média & 26.8 & 5.8 & 49.0 & 3.8 & 1.0 & 1.5 \\
\hline & & DP & 0.4 & 2.3 & 24.0 & 0.4 & 0.0 & 0.0 \\
\hline
\end{tabular}




\section{ASPECTOS BIOLÓGICOS}

A abordagem metodológica com utilização de Macroinvertebrados como bioindicadores na avaliação de impactos ambientais tem sido amplamente desenvolvida no mundo todo, principalmente na comparação entre habitats alterados e preservados (MOULTON, 1998; SHIMIZU, 1999).

Segundo Junqueira e Heckman (1998) é extremamente importante o uso de bioindicadores em estudos da qualidade da água. Segundo os mesmos autores, trata-se de uma ferramenta imprescindível para caracterizar determinado ambiente e seus microhabitats.

Foram coletados 436 espécimes, distribuídos em 10 ordens: 100 Molusca, 119 Crustacea, 96 Trichoptera, 48 Heteroptera, 22 Odonata, 20 Plecoptera, 17 Diptera, 8 Coleoptera, 4 Megaloptera, 2 Ephemeroptera (Tabela 2; Figura 9).

Tabela 2- Número total de Macroinvertebrados coletados nos igarapés Piranguinha, Toca do Índio e Capanema - PA.

\begin{tabular}{|c|c|c|c|c|}
\hline Ordem & Família/Espécie & PI & TI & CA \\
\hline \multirow{2}{*}{ Crustacea } & Paleomonidae: Carteri & 4 & 9 & 0 \\
\hline & Macrobrachium surinamicum & 32 & 46 & 20 \\
\hline \multirow{3}{*}{ Mollusca } & Trichodactilydae: Valdivia serrata & 2 & 2 & 4 \\
\hline & Pilidae: Pomacea & 0 & 0 & 100 \\
\hline & Polycentropodidae & 0 & 0 & 27 \\
\hline \multirow{2}{*}{ Trichoptera } & Hydropsychidae: Macronema & 41 & 14 & 0 \\
\hline & Hydrobiosidae: Atopsyche & 3 & 11 & 0 \\
\hline \multirow[t]{3}{*}{ Plecoptera } & Anacroneuria marlieri & 9 & 4 & 0 \\
\hline & Anacroneuria minuta & 4 & 2 & 0 \\
\hline & Anacroneuria sp & 1 & 0 & 0 \\
\hline \multirow{9}{*}{ Heteroptera } & Naucoridae: Limnocoris & 3 & 10 & 1 \\
\hline & Pelocoris & 1 & 1 & 0 \\
\hline & Gerridae: Trepobates & 0 & 1 & 0 \\
\hline & Lmnogonus & 3 & 0 & 3 \\
\hline & Veliidae: Raghovelia & 1 & 9 & 2 \\
\hline & Stridulivelia & 0 & 3 & 1 \\
\hline & Belostomatidae: Belostoma & 1 & 2 & 2 \\
\hline & Notonectidae: Bиепоа & 0 & 2 & 0 \\
\hline & Nepidae: $\quad$ Ranatra & 0 & 2 & 0 \\
\hline \multirow{9}{*}{ Odonata } & Megapodagrionidae:Heteragrion & 0 & 1 & 0 \\
\hline & Libellulidae: & 0 & 0 & 0 \\
\hline & Perithemis & 2 & 0 & 2 \\
\hline & Orthemis & 3 & 0 & 2 \\
\hline & Planiplax & 2 & 0 & 0 \\
\hline & Calopterygidae & 0 & 0 & 2 \\
\hline & Coenagrionidae: Oxyagrion & 1 & 1 & 0 \\
\hline & Gomphidae: Progomphus & 0 & 1 & 2 \\
\hline & Cyanogomphus & 2 & 1 & 0 \\
\hline Megaloptera & Corydalidae: Corydalus batesii & 2 & 2 & 0 \\
\hline Ephemeroptera & Euthyplociidae: Campylocia & 0 & 2 & 0 \\
\hline \multirow{2}{*}{ Diptera } & Tipulidae: Pedycia sp & 3 & 0 & 2 \\
\hline & Chironomidae: Chironomus sp & 0 & 1 & 11 \\
\hline \multirow{2}{*}{ Coleoptera } & Gyrinidae: Gyretes dorsalis & 0 & 7 & 0 \\
\hline & Dytiscidae: Gyretes sp. & 0 & 1 & 0 \\
\hline Total & & 120 & 135 & 181 \\
\hline
\end{tabular}

Fonte: autores (2018) 
Figura 9 - Número de espécimes coletados por igarapé no município de Capanema, Pará nos igarapés Piranguinha, Toca do Índio e Capanema - PA.

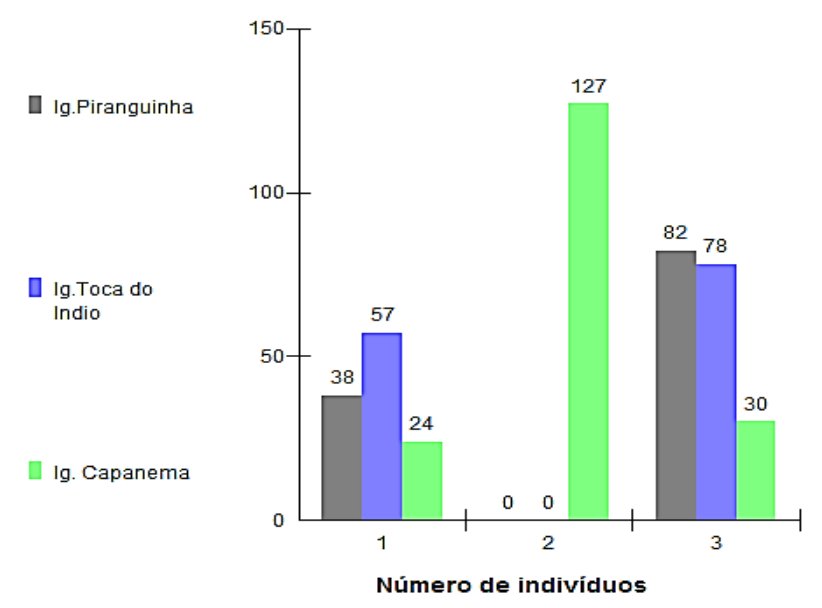

Fonte: autores (2018)

O grupo com maior número de indivíduos foi Molusca com um gênero (Pomacea); seguida de Crustacea com dois gêneros (Macrobrachium surinamicum e Paleomonetes carteri); Trichoptera com dois gêneros (Macronema e Atopsyche), Heteroptera com nove gêneros (Limnocoris, Pelocoris, Trepobates, Lmnogonus, Raghovelia, Stridulivelia, Belostoma, Buenoa e Ranatra); Odonata com oito gêneros (Heteragrion, Perithemis, Orthemis, Planiplax, Perilestes, Oxyagrion, Progomphus e Cyanogomphus); Plecoptera com um gênero (Anacroneuria marlieri, A. minuta e A. manauensis); Diptera com três gêneros (Chironomus e Pedycia); Coleoptera com um gênero (Gyretes dorsalis e Gyretes sp.); Megaloptera com um gênero (Corydalus batesii) e Ephemeroptera com um gênero (Campylicia). A família com maior número de indivíduos foi Paleomonidae, seguida de Trichodactylidae.

Abílio et al. (2007) realizaram estudos na bacia hidrográfica do rio Taperoá, em oito ambientes diferentes, utilizando para a análise de abundância e frequência de categorias propostas por Merritt e Cumins (1984), para insetos, moluscos, crustáceos e anelídeos. No presente estudo utilizamos apenas uma estatística descritiva para analisar a abundância dos espécimes coletados em cada igarapé. Os dados deste estudo não são comparáveis aqueles obtidos no rio Taperoá, que analisaram vários corpos d'água no semiárido da Paraíba.

Uma estatística descritiva foi utilizada com o índice de Shannon-Wiener para analisar a homogeneidade do número de indivíduos entre os igarapés. Os resultados mostram maior homogeneidade no igarapé Toca do índio (1.5315), seguido do igarapé Piranguinha com $(0,9303)$ e igarapé Capanema com $(0,6876)$, indicando o igarapé Capanema com menor homogeneidade. A heterogeneidade foi de (0.3925) no igarapé Piranguinha, (0.3109) no igarapé Toca do Índio e (0.5510) no igarapé Capanema (Tabela 3).

Tabela 3 - Índice de Shannon-Wiener e número total de Macroinvertebrados coletados nos igarapés Piranguinha, Toca do Índio e Capanema - PA.

\begin{tabular}{cccc}
\hline Pontos amostrais & Ig. Piranguinha & Ig. Toca do índio & Ig. Capanema \\
\hline Tamanho da amostra & 120 & 135 & 181 \\
Shannon-Wiener & 0.9303 & 1.09553 & 0.6876 \\
Máxima diversidade & 1.5315 & 1.5315 & 1.5315 \\
Homogeneidade & 0.6075 & 0.6891 & 0.4490 \\
Heterogeneidade & 0.3925 & 0.3109 & 0.5510 \\
\hline
\end{tabular}

Fonte: autores (2018)

Estudos realizados com comunidades de Macroinvertebrados no Brasil Central e Sudeste (Bueno et al., 2003; Abílio et al., 1997) mostram diferenças na abundância e riqueza de espécimes quando adotam os mesmos métodos estatísticos, estes estudos não podem ser comparados com os 
dados apresentados aqui, entretanto, há uma semelhança quando comparamos a riqueza e abundância dos espécimes em seus respectivos habitats.

Os mesmos dados são observados quando aplicamos o Índice de Simpson, com maior valor no igarapé Toca do Índio, seguido do igarapé Piranguinha e Capanema. Uma correlação Linear de Pearson foi aplicada entre os fatores abióticos e o número de espécimes coletados nos três igarapés, indicando forte correlação positiva $(p=0.0001)$ entre os igarapés Piranguinha e Toca do Índio (Tabela 4, Figura 10). A maior abundância foi observada nos grupos de Crustacea e Mollusca, seguida de Insecta: Trichoptera, Plecoptera e Heteroptera.

Tabela 4 - Índice de Simpson analisados nos igarapés Piranguinha, Toca do Índio e Capanema, Pará.

\begin{tabular}{cccc}
\hline Pontos amostrais & Ig. Piranguinha & Ig. Toca do índio & Ig. Capanema \\
\hline Tamanho da amostra & 120 & 135 & 181 \\
Índice de Simpson & 0.7994 & 0.8461 & 0.6549 \\
Índice de diversidade & 0.2006 & 0.1539 & 0.3451 \\
\hline
\end{tabular}

Fonte: autores (2018)

Apesar do grande avanço tecnológico investido em programas de biomonitoramento, ainda há grandes lacunas no que diz respeito à natureza e magnitude dos impactos ecológicos. Existem limitações para se fazer uma boa avaliação com biomonitoramento de insetos, uma delas, reside na dificuldade da escolha de técnicas de monitoramento que tornem possível isolar os efeitos das variabilidades espacial e temporal de efeito antrópico.

Figura 10 - Índice de Shannon-Wiener, indicando a riqueza e equitabilidade das amostras nos igarapés Piranguinha,

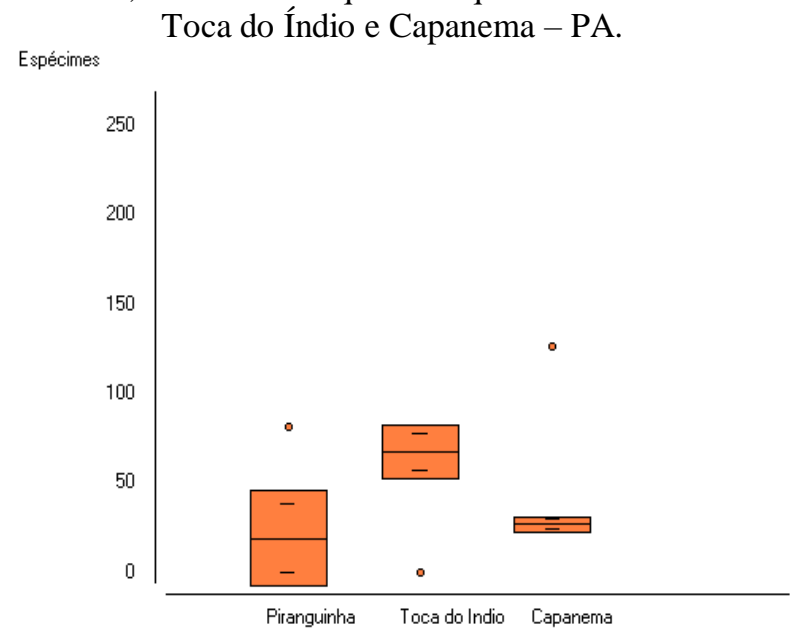

Fonte: autores (2018)

A Amazônia oriental apresenta elevada taxa de ocupação, com consequente avanço de ações antrópicas sobre o ambiente. Também agravante é a elevada taxa de ocupação e o investimento aplicado na utilização dos recursos naturais. Não há preocupação com a manutenção da qualidade da água dos rios e igarapés, por isso estudos desta natureza são importantes para, pelo menos, mostrar o quanto precisamos estudar a fauna de nossos rios e igarapés antes que seja tarde demais.

\section{CONCLUSÃO}

A fauna de Macroinvertebrados dos três igarapés possui diferenças significativas quando comparadas aos fatores abióticos e ao número de espécimes coletadas.

Os igarapés Piranguinha e Capanema foram os que apresentaram maior diferença quando correlacionado aos fatores físico-químicos da água. 
O igarapé Capanema é o que está mais degradado em ralação aos igarapés Piranguinha e Toca do Índio.

Os grupos que se destacaram quanto ao número de espécimes coletados foram: Crustacea, Molusca e Insecta (Trichoptera, Heteroptera e Plecoptera).

\section{RECOMENDAÇÃO}

O igarapé Capanema possui em alguns trechos de seu leito um alto grau de degradação e poluição ambiental e precisa urgentemente de um programa de recuperação de seu leito e suas margens, caso contrário, será mais um igarapé que desaparecerá em um curto espaço de tempo levando junto certamente a reduzida entomofauna aquática que ali vive.

\section{REFERÊNCIAS}

ABÍLIO, F. J. P. Gastrópodes e outros invertebrados bentônicos do sedimento litorâneo e associado a macrófitas aquáticas em açudes do semiárido Paraibano nordeste do Brasil. 2002. 175 p. Tese (Doutorado em Ecologia e Recursos Naturais). Universidade Federal de São Carlos, São Carlos-SP. 2002.

ABÍLIO, F. J. P.; RUFFO, T. L. M.; SOUZA, H. F. F.; FLORENTINO, H. S.; OLIVEIRA-JUNIOR, E. T.; MEIRELES, B. N.; SANTANA, A. C. D. Macroinvertebrados bentônicos como bioindicadores de qualidade ambiental de corpos aquáticos da Caatinga. Oecol. Bras., v.11, n.3, p. 397- 409. 2007.

CARVALHO, E. M.; UIEDA, V. S. Colonização por macroinvertebrados bentônicos em substrato artificial e natural em um riacho da serra de Itatinga, São Paulo, Brasil. Revista brasileira de Zoologia, v.21, n.2, p.287-293.2004.

COSTA, C. (ed). Insetos Imaturos. Metamorfose e Identificação. Ribeirão Preto: Holos. 2006.

EATON, D. P. Macroinvertebrados aquáticos como indicadores ambientais da qualidade de água. In: CULLEN, J.; RUDRAN, R.; VALLADARES-PADUA, C. (Org.), Métodos de estudo em biologia da conservação e manejo da vida silvestre. Curitiba: UFPR. 2003, p.43-67

ESTEVES, F. A. Fundamentos de Limnologia. Interciência. $2^{\mathrm{a}}$ ed. Rio de Janeiro: Interciência, 1998.

IBGE. 2011. http/WWW.ibge. Acessado em 12/10/2011..

MERRITT, R. W.; CUMMINS, K. W. An Introduction to the Aquatic Insects of North America. (second edition). Kendall/Hunt Plub. Co. Dubuque, USA 722p.1984.

MERRITT, R. W.; CUMMINS, K. W. An Introduction to the Aquatic Insects of North America. 3th Edition. Iowa. Kendall/Hunt Publishing Company. 1996.

MONTEIRO. E. S. Simuliidae (Diptera: Nematocera) associados as bacias lestes do Estado do Pará, com ênfase na Serra dos Martírios-Andorinhas. 2008. 178 p. Tese (Doutorado em Zoologia). Universidade Federal do Pará e Museu Paraense Emílio Goeldi, Belém Pará. 2008. 
MOULTON, T. P. Saúde e integridade do ecossistema e o papel dos insetos aquáticos. In: NESSIMIAN, J. L.; CARVALHO. A. L. (Eds), Ecologia de Insetos Aquáticos. Serie Oecologia Brasiliensis. PPGE-UFRJ, Rio de Janeiro, Brasil, p. 281-298.1998.

PÉREZ, G. R. Guía para el estudio de los macroinvertebrados acuáticos del Departamento de Antioquia. Bogotá, Fondo Fen Colômbia, Colciencias/Universidad de Antioquia. 1988.

SMITH, G. R., VAALA, D. A.; DINGFELDER, H. A. Distribution and abundante of macroinverterbrates within two temporare ponds. Hydrobiologia, n.497, p.161-167.2003.

TOWNES, H. A ligth-weight Malaise trap. Entomology News, n.83, p.239-247.1972.

VIDAL-ABARCA, M.R.; SUÁREZ, M. L.; GÓMEZ, R.; GUERREIRO, C.; SÁNTEZ-MONTOYA, M.M.; VELASCO, J. Intre-anual variation in benthic organic matter in a saline, semi-arid stream of southeaste Spain (Chicamo stream). Hydrobiologia, n.523, p.199-215.2004.

Wetzel, R.G. Limnology. 2.ed. Philadelphia: Saunders, 1983. 767p.

José Moacir Ferreira Ribeiro Doutor em Entomologia Museu Paraense Emílio Goeldi

ribeiroimf@hotmail. Zilda de Fátima Costa

Ieda Maria da Silva

Antônio Pereira Júnior Mestre em Ciências Ambientais Universidade do Estado do Pará Departamento de Engenharia Ambiental antonio.junior@uepa.br

Edmir dos Santos Jesus Doutor em Ciências Meteorológicas Universidade do Estado do Pará. Departamento de Engenharia Ambiental. edmir.jesus@gmail.com 